\title{
ANOMALIAS DO ESMALTE DENTAL: ETIOLOGIA, DIAGNÓSTICO E TRATAMENTO
}

\section{ANOMALIES IN DENTAL ENAMEL: ETIOLOGY, DIAGNOSTIC AND TREATMENT}

\author{
Andrea de Oliveira Ribas', Gislaine Denise Czlusniak² \\ 1 Autor para contato: Escola de Aperfeiçoamento Profissional - ABO, Ponta Grossa, \\ PR, Brasil; (45) 264-1467 ou (45) 264-2651 - Medianeira; \\ e-mail: andrea_ribas@bol.com.br \\ 2 Universidade Estadual de Ponta Grossa, Campus em Uvaranas, Departamento de \\ Odontologia, Escola de Aperfeiçoamento Profissional - ABO de Ponta Grossa, PR, \\ Brasil; (42) 220-3111; e-mail: g.czlusniak@brturbo.com
}

Recebido para publicação em 28/11/2003

Aceito para publicação em 20/04/2004

\section{RESUMO}

A proposta deste trabalho foi realizar uma revisão de literatura minuciosa sobre as anomalias do esmalte dental, que resultam da ação de vários fatores etiológicos durante os estágios de aposição e mineralização do desenvolvimento dentário. Embora as características clínicas sejam semelhantes, os fatores etiológicos podem ser sistêmicos, locais ou genéticos, desencadeando hipoplasias de esmalte em dentes isolados, grupos de dentes, ou mesmo em todos eles, nas dentaduras decídua e permanente. De acordo com o grau de severidade dessas anomalias, vários protocolos de tratamento podem ser realizados, desde clareamento, microabrasão, restaurações estéticas conservadoras e reabilitações protéticas. Portanto, por meio de um diagnóstico diferencial preciso, buscar-se-á um tratamento efetivo e eficaz para restabelecer a função, a estética e a auto-estima de pacientes que sejam portadores de hipoplasia de esmalte.

Palavras-chave: anomalias de esmalte, hipoplasia de esmalte, amelogênese imperfeita

\begin{abstract}
The aim of this work was to revise the pertinent literature concerning anomalies of dental enamel, resulting from various causative factors during
\end{abstract}


the stages of apposition and mineralization of tooth development. Although the clinical aspects are similar, the ethiological factors may be local, systemic or genetic, leading to hipoplasias of the enamel in isolated teeth, in groups of teeth, or even in all teeth, in both deciduous and permanent dentition. Depending on the degree of severity of these anomalies, various protocols of treatment may be practiced, including whitening, microabrasion, aesthetic conservative restorations and prosthetic rehabilitation. However, by means of a precise diagnostic process and an effective and efficient treatment is sought, to reestablish the functioning, the aesthetic appearance and the selfesteem of patients who suffer from enamel hypoplasia.

Key words: enamel anomalies, enamel hypoplasia, amelogenesis imperfecta

\section{Introdução}

A harmonia estética é um anseio que cada vez mais vem preocupando a população, que busca atendimento odontológico especializado. Os parâmetros de estética impostos pela sociedade vêm fazendo com que as pessoas que apresentam hipoplasia de esmalte busquem cada vez mais tratamentos e métodos preventivos adequados para cada tipo desta alteração.

Os distúrbios de desenvolvimento no esmalte apresentam-se como anomalias de estrutura, podendo afetar ambas as dentições, tendo caráter sistêmico, local ou hereditário.

O profissional deve estar preparado para realizar um correto diagnóstico frente à presença de alterações no esmalte dental. É de grande importância o conhecimento dos diferentes tipos de hipoplasia, para que por meio de uma anamnese minuciosa se possa detectar a causa e o tipo de mancha intrínseca que o paciente apresenta, determinando assim, o tratamento mais adequado e um prognóstico favorável.

Dessa forma, o objetivo do presente trabalho é buscar respaldo científico na literatura para que se possa elucidar as indagações sobre etiologia, diagnóstico e tratamento das anomalias do esmalte dental.

\section{Revisão de Literatura}

McDonald, em 1977, citou que a hipoplasia de esmalte pode ser desencadeada por fatores sistêmicos, locais ou hereditários, ocasionando defeitos e irregularidades na superfície do esmalte. Esse tipo de alteração poderá apresentar-se de forma suave, o que resultará numa corrosão da superfície do esmalte, ou se manifestar desenvolvendo uma linha horizontal na coroa dental. Se a atividade ameloblástica for interrompida por um longo período de tempo, surgirão extensas áreas de formação de esmalte irregular ou imperfeito. A ocorrência da hipoplasia pós-natal dos dentes decíduos provavelmente é tão comum quanto a ocorrência de hipoplasia em dentes permanentes, mas geralmente se apresenta de forma menos severa. Entretanto, a hipoplasia de esmalte nos dentes decíduos pré-natais é rara.

A hipoplasia de esmalte pode ser conseqüência de eventos sistêmicos, traumáticos, ambientais ou genéticos que ocorrem durante o desenvolvimento dos dentes, interferindo na formação normal da matriz do esmalte, causando defeitos e irregularidades na sua superfície. Podem se apresentar como manchas esbranquiçadas, irregulares, rugosas, ou ainda, sulcos e ranhuras, bem como outras alterações na estrutura do esmalte (Shafer et al., 1987).

Clinicamente, a hipoplasia de esmalte manifesta-se com falta total ou parcial da superfície de esmalte, apresentando uma estética insatisfatória, dentes sensíveis, má-oclusão, bem como predisposição à cárie dental (Seow, 1991).

Segundo Oliveira e Rosenblatt (2002) a ocorrência de defeitos de esmalte na dentição decídua é comum e o odontopediatra tem grande 
responsabilidade na sua detecção e acompanhamento, já que as alterações que ocorrem na sua estrutura podem acarretar o aparecimento de cárie precoce na infância.

\section{Hipoplasia Sistêmica}

McDonald (1977) citou várias causas e formas de manifestação de hipoplasia sistêmica, como: hipoplasia devido a deficiências nutricionais, em que os estados carenciais que podem estar relacionados com a ocorrência de hipoplasia de esmalte estariam associados a deficiências de vitaminas A, C e D, cálcio e fósforo, e hipoplasia relacionada com traumatismos cerebrais e defeitos neurológicos, onde foi detectada a existência da relação entre a época em que os possíveis fatores etiológicos causaram o dano cerebral e a época de formação do esmalte defeituoso. Sendo assim, a presença de hipoplasia de esmalte ajudará o clínico a detectar a época em que o traumatismo cerebral ocorreu, nos casos em que a etiologia não está definida, hipoplasia devido à radiação $\mathrm{X}$, poderá ser encontrada, nos dentes permanentes, linha de esmalte hipoplásico, que se associa à época do estágio do desenvolvimento do dente e à terapia anti-neoplásica realizada, e hipoplasia devido a fluoretos (fluorose dental).Uma das manifestações da fluorose dental é através da água de consumo que contenha mais de uma parte por milhão (ppm) de flúor, podendo afetar o ameloblasto durante a formação do dente, resultando num quadro clínico conhecido como "esmalte manchado”, porém a aparência do esmalte afetado pelo consumo de água com excesso de flúor varia consideravelmente. Segundo o autor existem poucas evidências para afirmar que dentes hipoplasiados são mais suscetíveis à cárie do que dentes normais. Porém lesões de cárie podem se desenvolver em defeitos de esmalte. Pequenas lesões de cárie e áreas pré-cariosas podem ser restauradas com materiais resinosos, lembrando que a restauração é sempre restrita à área envolvida. Os dentes decíduos e permanentes hipoplásicos que apresentam largas áreas de esmalte defeituoso e dentina exposta, logo que irrompem podem se apresentar sensíveis. Restaurações satisfatórias nessa época são freqüentemente impossíveis, então pode ser realizada a aplicação tópica de fluoreto estanoso a oito por cento quantas vezes for necessário para ocorrer a redução de sensibilidade dos dentes afetados.

Shafer et al. (1987) definem hipoplasia de esmalte como uma formação incompleta ou defeituosa da matriz orgânica do esmalte dentário. Diferentes fatores, são capazes de causar dano aos ameloblastos, tais como: deficiências nutricionais (vitaminas A, C e D), febre exantematosa e doenças exantematosas (sarampo, varicela e escarlatina), sífilis congênita (envolve geralmente os incisivos permanentes superiores e inferiores e os primeiros molares), hipocalcemia (neste caso, a hipoplasia está relacionada com a ocorrência da tetania, provocada pela baixa do nível do cálcio no sangue), traumatismo por ocasião do nascimento, excesso de flúor (fluorose dental) e fatores idiopáticos (muitos estudos clínicos mostram, que mesmo com histórias e levantamentos cuidadosos, em alguns casos a hipoplasia de esmalte é de origem desconhecida). Em geral, pode-se afirmar que qualquer deficiência nutricional ou doença sistêmica séria pode ser capaz de produzir hipoplasia de esmalte, já que os ameloblastos constituem um dos grupos de células mais sensíveis do corpo, no que diz respeito à função metabólica. Entretanto, a hipolasia de esmalte só aparece se a injúria ocorrer na época em que os dentes estão em desenvolvimento, ou mais especificamente, durante a fase de formação do esmalte. Depois do esmalte estar mineralizado, não existe mais risco de ocorrer defeitos. Estudos clínicos indicam que dentes hipoplásicos são mais suscetíveis à presença e evolução de lesões cariosas, embora os dois fatores não estejam relacionados.

Segundo Seow (1991), nos dentes decíduos são fatores ambientais que alteram o esmalte dental durante o período de formação. No entanto, suas manifestações clínicas são mais suaves, já que o período de formação e a espessura do esmalte dos dentes decíduos são menores.

Needleman et al. (1992) relatam que alterações no desenvolvimento pré, peri e pós-natal, envolvendo a secreção e/ou maturação da matriz do esmalte, podem agir como marcas permanentes, devido à estabilidade estrutural que o esmalte apresenta. Certas condições, como associadas a 
fatores químicos (flúor, tetraciclina e talidomida), infecciosos (virais e bacterianos), metabólicos (diabetes, hipocalcemia, hipotireoidismo e má absorção gastrointestinal), neurológicos, nutricionais (deficiência de vitaminas A e D), distúrbios respiratórios, distúrbios perinatais (prematuridade, baixo peso ao nascer), rubéola, hipoxia cerebral, desnutrição, raquitismo e sarampo têm uma associação muito próxima com o aparecimento de hipoplasia de esmalte nos períodos pré e pós-natal de desenvolvimento do esmalte dental.

Para Coutinho e Portella (1995), o principal objetivo do tratamento de pacientes que apresentam hipoplasia de esmalte sistêmica, é proporcionar uma reabilitação que promova completa reconstituição estética e devolva também a função mastigatória. Devido aos novos materiais disponíveis e técnicas restauradoras mais conservadoras, a reabilitação proveniente do tratamento devolveu ao paciente efeito estético, funcional e também psicológico. Portanto, uma paciente que inicialmente se apresentava tímida e retraída pode voltar a sorrir e tornarse mais comunicativa, o que para o profissional odontopediatra é muito gratificante. Sendo assim, a realização de um diagnóstico precoce com a finalidade de ser instituído um pronto atendimento, evitando o desgaste total dos dentes hipoplásicos, através da atrição e conseqüente extração dos mesmos para instalação de próteses é de grande importância.

Pinkham et al., em 1996, citaram formas de manifestações da hipoplasia de esmalte originadas por fatores sistêmicos: deficiências nutricionais (vitaminas A, C e D, assim como cálcio e fósforo), infecções severas (doenças exantemáticas e desordens geradoras de febre), sífilis causada pelo treponema pallidum, produz padrões clássicos de dismorfia hipoplásica nos dentes permanentes (incisivos de Hutchinsons e molares em amora); defeitos neurológicos; crianças com asma (apresentam grande freqüência de hipoplasia de esmalte quando comparadas às não afetadas); prematuridade; radiação $\mathrm{X}$; excesso de ingestão de flúor (fluorose dental), e várias síndromes também podem estar associadas com hipoplasia de esmalte sistêmica.

Toledo (1996) relatou que a hipoplasia de esmalte sistêmica atinge grupos dentários quando uma doença infecciosa da infância provoca alteração na atividade ameloblástica. Sendo assim, somente as áreas que estão se desenvolvendo no momento da infecção vão manifestar as alterações estruturais.

Corrêa (1998) relata que a hipoplasia de esmalte sistêmica raramente é observada na dentição decídua. Essa hipoplasia afeta grupo de dentes que têm a mesma época de formação e estão vinculados a doenças sistêmicas crônicas prolongadas ou a medicamentos ingeridos durante o período de formação dos dentes afetados.

Durante o período gestacional, os pais devem ser conscientizados quanto aos hábitos de higiene bucal, por meio de controle de cárie, doenças periodontais e visitas periódicas ao cirurgiãodentista, e a gestante ser submetida a uma dieta balanceada. Infecções virais e bacterianas, como ocorre nas febres, são prejudiciais à formação dos dentes do feto, pois os ameloblastos são sensíveis a altas temperaturas e ficam sujeitos às alterações nos seus padrões de deposição de cálcio (Carvalho et al., 2000). Estes mesmos autores citam alguns medicamentos que não devem ser prescritos à gestante, como a tetraciclina e os antiinflamatórios não esteróides derivados do ácido pirazolônico, que têm o poder de atravessar a barreira placentária podendo alterar a pigmentação da coroa dos dentes decíduos e permanentes. Estes medicamentos podem levar ao desenvolvimento dos dentes com hipoplasia de esmalte, devido à má formação do esmalte dental.

Gerlach et al. (2000) relataram que o esmalte dental é formado por células extremamente sensíveis a alterações sistêmicas. Um dos motivos da sensibilidade é o fato dos ameloblastos serem células epiteliais, com grande síntese protéica. Portanto, alterações nutricionais, distúrbios de perfusão vascular, bem como distúrbios no metabolismo de cálcio levam a alterações do esmalte. Alterações mais severas podem estar relacionadas com menor tempo de gestação, asfixia neonatal, baixo peso ao nascimento e desnutrição. Existem substâncias que quando ingeridas pela mãe durante a gestação, ou pela criança, podem resultar em defeito do esmalte, como flúor, tetraciclina e talidomida. E, existe grande preocupação em relação à ingestão de flúor, devido 
à ocorrência de fluorose, que ocorre pelo excesso de flúor na água de abastecimento de algumas regiões, ou até mesmo porque algumas crianças, dependendo da idade, engolem grande parte do creme dental durante a fase de formação do esmalte. Infecções virais (rubéola materna), algumas doenças que interferem no metabolismo de cálcio (hipotireoidismo, hipoparatireoidismo e diabete materna não controlada) e doença hemolítica do recém-nascido podem ocasionar defeitos de esmalte, de ordem sistêmica. É muito importante um cuidadoso exame clínico para que o cirurgiãodentista chegue ao diagnóstico correto, pois o conhecimento odontológico dos defeitos de esmalte pode contribuir para a saúde global do paciente.

Para Valente e Modesto (2001) o paciente portador de deficiência, seja ela física ou mental, deve ser atendido por uma equipe multidisciplinar para que suas necessidades sejam abordadas de forma ampla, proporcionando-lhe melhor qualidade de vida.

Waes e Stöckli, em 2002, relataram que hipoplasia de esmalte ocasionada por doenças sistêmicas ocorre freqüentemente. $\mathrm{O}$ tipo e a forma da displasia são dependentes do estado de desenvolvimento dos dentes atingidos, bem como do momento, duração (aguda ou crônica) e da intensidade da influência. Diferentes influências podem causar falhas semelhantes ou idênticas, tais como: radiação X, alterações metabólicas, celiaquia, subnutrição e desnutrição, fatores idiopáticos (são os casos onde ocorrem displasias nos primeiros molares permanentes sem explicações aparentes e atinge cerca de $7 \%$ das crianças), e hipoplasia em forma de canaleta (todas as partes da coroa que estavam em formação no momento do distúrbio manifestam alterações quantitativas no esmalte). As alterações no esmalte dental variam desde pequenas manchas até graves hipoplasias e não precisam ser idênticas em todos os dentes formados no mesmo período.

\section{Hipoplasia Local}

McDonald, em 1977, relatou que hipoplasia de esmalte local ocorre devido a fatores que vão interferir na formação normal da matriz ocasionando defeitos e irregularidades na superfície do esmalte que são causados através de infecção local ou trauma. Turner foi o primeiro a descrever hipoplasia local, quando notou defeitos no esmalte de dois prémolares e os relacionou à infecção apical que havia ocorrido nos molares decíduos. Sendo assim, a hipoplasia de esmalte causada por infecção local, hoje é conhecida como "hipoplasia de Turner".

Segundo Shafer et al. (1987) hipoplasia de esmalte localizada ocorre devido a traumatismo ou infeç̧ão local. Geralmente acomete incisivos superiores permanentes ou pré-molar superior ou inferior. Essa hipoplasia pode variar de uma pigmentação acastanhada e moderada do esmalte à presença de fossetas profundas e irregularidades na coroa do dente. Casos de dentes alterados por infecção local, são denominados de "dentes de Turner". Quando ocorre infecção devido à presença de cárie no dente decíduo e o sucessor permanente está em formação, a infecção bacteriana pode envolver o tecido periapical do dente decíduo, podendo perturbar a camada ameloblástica do permanente, resultando numa coroa hipoplásica. A gravidade da hipoplasia depende da gravidade da infecção, do grau do envolvimento tecidual e da fase da formação do dente permanente, durante a qual ocorreu infecção no dente decíduo. Outro fato que pode ocorrer é a intrusão de um dente decíduo, com alteração do broto do dente permanente. Se a coroa do dente permanente ainda estiver em formação, o dano pode manifestar-se como uma pigmentação ou mancha amarelada ou acastanhada do esmalte.

Marangoni e Carvalho, em 1992, avaliaram algumas formas de restabelecer a estética em dentes anteriores acometidos por hipoplasia de esmalte envolvendo apenas um elemento dentário. As soluções relatadas foram o uso de coroas totais em metalocerâmica, facetas estéticas em porcelana ou restaurações estéticas, com o uso de resina composta. A utilização da resina composta tem como vantagem a menor necessidade de desgaste de estrutura dentária e a execução em apenas uma sessão. Portanto, é importante ressaltar que através de associação de materiais e técnicas adesivas podese resolver casos estéticos com o mínimo de destruição de tecido dentário.

Toledo (1996) relatou que a hipoplasia de esmalte local ocorre quando a disseminação de uma infecção periapical ou um traumatismo em dente 
decíduo perturbarem a atividade formadora dos ameloblastos do dente permanente substituto. Os dentes permanentes atingidos pelo defeito estrutural são nesse caso, chamados de "dentes de Turner".

Segundo Corrêa (1998) a hipoplasia local raramente ocorre na dentição decídua.

Gerlach et al. (2000) descreveram que o trauma é uma das causas mais conhecidas de hipoplasia local. Nos dentes decíduos durante a entubação endotraqueal pode ocorrer o trauma do osso em desenvolvimento. Nos dentes permanentes, o trauma pode ocorrer envolvendo o dente decíduo antecessor, o que leva ao defeito do esmalte no permanente sucessor.

Para Alexandre et al. (2000), os traumatismos na dentição decídua são muito comuns na clínica odontológica, porém são problemas de difícil prevenção em função da faixa etária em que ocorrem. Saber quando, onde e como aconteceu o traumatismo dentário é de grande importância para se estabelecer um diagnóstico preciso durante o atendimento emergencial, para posterior planejamento do tratamento definitivo. O principal objetivo do cirurgião-dentista frente a uma situação de traumatismo dentário é tentar evitar maiores danos aos dentes envolvidos, principalmente para o germe do dente permanente. As causas dos traumatismos dentários são várias e o maior número de acidentes ocorre em casa, na dentição decídua e na dentição permanente, na escola. A freqüência dos traumatismos dentários varia de acordo com: idade, gênero, local, tipo de traumatismos e fatores predisponentes. Ocorrem em meninos e meninas na mesma proporção, apenas variando quanto à faixa etária. A luxação intrusiva corresponde ao traumatismo dentário que mais acomete a dentição decídua. O incisivo central superior é o dente mais freqüentemente envolvido nesses casos, sem haver diferença quanto ao lado. A intrusão do dente decíduo é o tipo de traumatismo que mais afeta o germe do dente permanente. A fim de evitar alterações no germe do dente permanente, o diagnóstico dos traumatismos dentários na dentição decídua deve ser rápido e preciso. É importante procurar saber se a criança bateu a cabeça na hora do acidente ou se há sinal de concussão cerebral, pois nesses casos o tratamento dentário deve ser adiado para após o restabelecimento do paciente. Os dentes intruídos geralmente reerupcionam espontaneamente de 1 a 6 meses após o traumatismo dentário, sendo que a sua impactação é muito rara. Durante essa fase é necessário que se faça acompanhamento clínico e radiográfico. Se houver alguma alteração durante a fase de acompanhamento, não reerupção do dente dentro do prazo esperado ou evidências clínicas e radiográficas de que o ápice do dente intruído foi deslocado em direção ao germe do dente permanente é necessário que se faça a exodontia do dente intruído imediatamente, prevenindo assim o avanço da infecção para o seu sucessor. O dano ao dente sucessor pode ocorrer tanto no momento do trauma quanto no período subseqüente. Quanto menor for a idade do paciente, mais graves serão as alterações de desenvolvimento, envolvendo a coroa do dente permanente. As luxações são responsáveis por 60 a $73 \%$ dos casos e a freqüência com que o desenvolvimento normal do dente permanente seja afetado após intrusão dos dentes decíduos pode chegar a $50 \%$ e a seqüela predominante encontrada nos dentes permanentes devido ao traumatismo dentário foi a hipoplasia de esmalte. Portanto, recomenda-se que os cirurgiões-dentistas, nas consultas de rotina, informem aos responsáveis pelos pacientes sobre a necessidade de atendimento imediato, caso venha a ocorrer traumatismo dentário.

Franco et al., em 2001, relataram que no intuito de recuperar a estética, muitas formas e técnicas de tratamento têm sido propostas para resolver casos de descoloração dentária, como: técnica de clareamento dental, microabrasão e restaurações diretas e indiretas em resina composta e porcelana. Quando o dente não estiver excessivamente danificado, pode-se optar por técnicas menos invasivas como o clareamento e a microabrasão, mas em casos de manchamento severo ou perda de estrutura dentária, procedimentos restauradores estão indicados.

Segundo Waes e Stöckli (2002) as causas locais e diretas determinam lesões de distribuição assimétrica, limitadas a dentes isolados e são definidas como hipoplasias locais. São ocasionadas por fatores como deslocamento traumático do dente 
decíduo, podendo causar, devido às estreitas relações topográficas entre a raiz do dente decíduo e o germe de seu sucessor, diferentes distúrbios na formação do esmalte, com intensidade da lesão variável, dependendo do trauma ocorrido. Outra manifestação é o "dente de Turner" que acomete cerca de um quarto dos sucessores de dentes decíduos infectados. Atingem os sucessores permanentes com alterações, desde opacidades até deformidades.

Hernandes et al. (2003) relataram que os traumatismos que acometem a dentição decídua merecem grande atenção e cuidado, pois podem atingir o germe do dente permanente. Quando ocorrer qualquer tipo de trauma, é fundamental o pronto-atendimento para que se possa ter um melhor prognóstico evitando ou minimizando assim as possíveis seqüelas. Aproximadamente $30 \%$ das crianças de 10 a 72 meses já sofreram algum tipo de trauma nos dentes decíduos, estando as crianças menores mais sujeitas e a região da maxila mais atingida. $\mathrm{O}$ fator psicológico dos pacientes que apresentam seqüelas de traumas na cavidade bucal deve ser avaliado, uma vez que após o tratamento geralmente ocorre melhora nos pacientes, pois os mesmos se apresentam mais receptivos e sociáveis. Portanto, crianças que sofreram qualquer tipo de trauma nos dentes decíduos devem ser periodicamente avaliadas, com a finalidade de diagnosticar precocemente qualquer tipo de alteração que possa prejudicar o desenvolvimento do sucessor permanente. A época de intervenção também é um fator importante na escolha do tratamento. Portanto quanto mais cedo for realizada a intervenção, melhor o prognóstico do paciente. No entanto, quando ocorre um planejamento consistente multidisciplinar deve-se ter como finalidade a plena recuperação anatômica, funcional e estética do paciente.

\section{Hipoplasia Hereditária (Amelogênese Imperfeita)}

McDonald (1977) definiu amelogênese imperfeita como uma alteração do esmalte dental que atinge tanto a dentadura decídua como a permanente, com inúmeras variações clínicas, quanto ao grau de severidade. É transmitida como um traço autossômico dominante, um traço dominante ligado ao sexo ou um traço recessivo ligado ao sexo. Radiograficamente o contorno pulpar tem forma normal e a raiz não é morfologicamente distinta dos dentes normais. O tratamento da amelogênese imperfeita depende da severidade e da necessidade de melhorar a estética.

Elzay e Chamberlain (1986) constataram que evidências radiográficas de câmaras pulpares aumentadas podem auxiliar a detectar a presença de taurodontismo associado a amelogênese imperfeita.

Para Shafer et al. (1987) amelogênese imperfeita é um distúrbio exclusivamente ectodérmico, pois os componentes mesodérmicos do dente se encontram basicamente normais. Constitui um grupo de defeitos hereditários do esmalte, não havendo associação com quaisquer outros defeitos generalizados. O desenvolvimento do esmalte normal ocorre em três etapas: etapa formativa, na qual há deposição da matriz orgânica; etapa de mineralização, onde a matriz é parcialmente mineralizada; etapa de maturação, durante a qual os cristais aumentam e completam-se. Sendo assim, são relatados três tipos básicos de amelogênese imperfeita, dependendo da etapa de formação do esmalte dental em que ocorre: tipo hipoplásico, onde há formação deficiente da matriz; tipo hipomineralizado, onde há mineralização deficiente da matriz formada; tipo hipomaturação, onde os cristais de esmalte permanecem imaturos. Segundo os mesmos autores o paciente portador de amelogênese imperfeita pode apresentar as coroas dentárias com ou sem alteração de cor. Já o esmalte pode estar totalmente ausente, como ter variação quanto a sua textura, consistência ou até mesmo ser relativamente duro. Os pontos de contato entre os dentes estão abertos e nas faces oclusais e bordas incisais ocorre abrasão acentuada. Radiograficamente o esmalte pode apresentar-se ausente, ou quando existente aparecer como uma fina camada, mais evidente sobre as pontas das cúspides e faces interproximais. Também pode ocorrer quando a mineralização do esmalte estiver muito afetado, parecer relativamente a mesma densidade radiográfica da dentina, tornando-se difícil a diferenciação entre os mesmos.

Bouvier et al. (1996) definiram amelogênese imperfeita como uma doença de caráter hereditário 
que afeta o esmalte de ambas as dentaduras; ocorrendo em incidência de 1 pessoa para 14000. Todos os dentes apresentam-se mal formados e manchados. A oclusão e a dimensão vertical são rapidamente afetadas pelo desgaste dos dentes, e essa insuficiência de esmalte torna os dentes extremamente sensíveis ao contato e estímulos térmicos. Nesse estudo, os autores citaram três etapas importantes para realização do tratamento da amelogênese imperfeita: tratamento emergencial temporário dos dentes decíduos ou permanentes, em que será realizado um tratamento breve dos dentes afetados, com a finalidade de diagnosticar se o paciente está preparado para cooperar durante a realização do tratamento definitivo, o que dependerá da idade e em que dentição o paciente se encontra; tratamento provisório ou transitório dos dentes permanentes, realizado quando todos os dentes permanentes (exceto os terceiros molares) tenham erupcionado. Essa etapa só será realizada se o paciente aceitar e/ ou permitir ter uma vida normal, até que um tratamento definitivo e permanente, porém mais complexo seja realizado. Nessa etapa, quando necessário, deve ser realizado o tratamento periodontal; tratamento definitivo dos dentes permanentes do paciente adulto. O tratamento necessita de motivação e envolvimento por parte do paciente jovem e a instalação de uma higiene oral satisfatória, pois o paciente que apresenta quadro de amelo-gênese imperfeita, pode apresentar dentes com esmalte fraco e forte sensibilidade dentária, sendo assim relutam em ter uma escovação adequada, o que acarreta muitas vezes em gengivite, mas raramente em cárie dental.

Segundo Pinkhamet al. (1996) de acordo com os estágios de desenvolvimento do esmalte dental, nos quais a amelogênese imperfeita ocorre, se dividem em subgrupos: tipo hipoplásica (ocorre no estágio de histodiferenciação), no qual uma entidade insuficiente de esmalte é formada. Afeta ambas as dentaduras, e a condição é herdada predominantemente como característica autossômica dominante.Tipo hipomaturado (ocorre na fase de aposição da matriz do esmalte), é caracterizado por dentes que possuem espessura de esmalte normal, mas apresentam um baixo valor de radiodensidade e conteúdo mineral. Tipo hipomineralizado (ocorre no estágio de mineralização da formação do esmalte), quantitativamente o esmalte é normal, mas qualitativamente a matriz é pobremente mineralizada com uma superfície de esmalte friável. O esmalte hipomineralizado é mole e frágil, especificamente nas regiões incisais, e facilmente fraturado, expondo a dentina, que produz uma aparência sem estética.

Para Corrêa (1998) a integridade dos dentes é difícil de ser preservada mesmo quando for realizada intervenção na primeira infância, devido ao comprometimento severo de todas as estruturas dentárias.

Para Jorge et al. (1999) não há possibilidade de se fazer tratamento preventivo em pacientes portadores de amelogênese imperfeita, dado a sua origem genética. Portanto, o tratamento para estes pacientes, é voltado somente para o aspecto estético.

Segundo Williams e Becker (2000) amelogênese imperfeita (displasia hereditária do esmalte) é um grupo de defeitos hereditários sem associação com outros distúrbios generalizados. Ocorre por meio de fatores genéticos (autossômicos dominante, recessivo ou ligado ao cromossomo $\mathrm{X}$ ), sendo uma alteração exclusivamente ectodérmica. Acomete 1 pessoa para 15000. Em casos de manifestações severas de amelogênese imperfeita, encontra-se comprometimento da oclusão e estética insatisfatória, fazendo-se necessário realizar plano de tratamento meticuloso através de um diagnóstico preciso e detalhado para restabelecer e recuperar a coroa dental, devolvendo harmonia entre oclusão, função e estética. É indicado uso de materiais modernos, (combinação de metais nobres, restaurações de porcelana e inlays). No entanto, é importante salientar que pacientes nascidos com defeitos de desenvolvimento dental não devem ser subestimados, pois o impacto psico-social gerado nesses pacientes é anti-estético e desagradável.

Pithan et al., em 2002, definiram amelogênese imperfeita como uma alteração de caráter hereditário que afeta o esmalte dentário em ambas as dentaduras, sendo um distúrbio de natureza totalmente ectodérmica, pois os componentes mesodérmicos do esmalte estão intactos. Esse distúrbio pode levar à sensibilidade por parte do paciente, devido à variação 
de temperatura e em $60 \%$ dos casos ocorrer instalação de mordida aberta anterior. O defeito estrutural causado pela amelogênese imperfeita leva os dentes afetados a serem mais suscetíveis a atrição, ocasionando diminuição da dimensão vertical. Um dos principais transtornos causados devido a essa alteração é a estética deficiente, que pode trazer problemas psicológicos aos pacientes. Medidas preventivas como aplicações tópicas de flúor e controle da dieta devem ser recomendados ao paciente. Os portadores de amelogênese imperfeita são predisponentes a problemas gengivais, pois há um incremento na retenção de placa e na formação de cálculo devido ao aumento da rugosidade da superfície de esmalte. Geralmente pacientes que apresentam amelogênese imperfeita são candidatos à terapêutica reabilitadora por coroas totais. Um dos motivos de se utilizar esse recurso é o aspecto estético que é seriamente afetado, pois os dentes apresentam-se de cor castanho escuro. O uso das coroas totais justifica-se também devido ao desgaste excessivo dos dentes, muitas vezes até o nível gengival.

Segundo Waes e Stöckli (2002) amelogênese imperfeita é uma displasia do esmalte de origem genética e tem como conseqüência alterações diversas. O esmalte formado é deficiente ou em qualidade anormal e a estrutura da dentina se apresenta normal. Os autores descrevem três manifestações mais comuns: amelogênese imperfeita hipoplásica (apresentam espessura reduzida do esmalte), e se manifestam nas formas lisas, ásperas, crateriformes e a maioria das formas locais. Os dentes têm a cor da dentina, mas são duros e podem adquirir mais tarde a cor castanho-amarelada. O risco de incidência de cárie é menor, mas a abrasão aumentada pode causar hipersensibilidade e danos irreversíveis à polpa. Amelogênese imperfeita por hipomaturação (os ameloblastos produzem a matriz do esmalte em quantidade normal, mas a mineralização é deficiente). A espessura do esmalte é normal, porém mais macio. Em casos mais graves, podem ocorrer perdas maciças de substâncias dentárias na área dos molares. Amelogênese imperfeita por hipomineralização (o esmalte tem espessura normal na erupção, mas é muito macio, opaco, sem brilho, e a coloração varia do branco até o castanhoclaro). Devido à abrasão e à atrição, o esmalte será perdido em poucos meses ou tomará coloração amarelo-escuro a marrom. Radiograficamente o esmalte mostra uma densidade igual ou até menor que a dentina. Há uma forte tendência à formação de tártaro dentário. Geralmente a mordida aberta está presente em quase todas as formas de manifestação de amelogênese imperfeita. O tratamento para amelogênese imperfeita inicia-se com um programa de prevenção, incluindo: instruções de higiene bucal, aconselhamento dietético, limpeza profissional e aplicação tópica de flúor. Indica-se a realização inicialmente de restaurações provisórias, com o objetivo de criar condições propícias para os procedimentos preventivos e assegurar o desenvolvimento da dentição sem distúrbios. O efeito preventivo pode ser prejudicado pela hipersensibilidade ou pelo excesso de retenção de placa bacteriana. Além disso, o importante é satisfazer as expectativas estéticas e funcionais do paciente, tanto quanto possível. Já a restauração definitiva deve ser realizada após o término do crescimento e tem como objetivo ser duradoura e ter elevado grau estético e funcional.

\section{Discussão}

A hipoplasia de esmalte ocorre em conseqüência de problemas sistêmicos, locais e hereditários, podendo afetar ambas as dentições. Estes fatores vão interferir na formação normal da matriz do esmalte dental, causando defeitos e irregularidades na sua superfície, ou seja, ocasionando uma formação incompleta ou deficiente da matriz orgânica (McDonald, 1977; Shafer et al., 1987; Seow, 1991).

A ocorrência de hipoplasia de esmalte em dentes decíduos é tão comum como em dentes permanentes, porém não ocorre de forma tão severa. Já, a hipoplasia de esmalte pré-natal é rara (McDonald, 1977; Oliveira e Rosenblatt, 2002).

A hipoplasia de esmalte sistêmica atinge grupos de dentes. Quando uma doença ou distúrbio 
infeccioso da infância provoca alteração na atividade ameloblástica, ou seja, as áreas que estavam se desenvolvendo no momento da infecção vão manifestar alterações estruturais. Depois do esmalte estar mineralizado, não existe mais risco de ocorrer defeitos (Shafer et al., 1987; Toledo, 1986; Corrêa, 1998). O tipo e a forma de apresentação da hipoplasia de esmalte sistêmica depende do estado de desenvolvimento dos dentes atingidos, bem como do momento, duração (aguda ou crônica) e intensidade da influência (Waes e Stöckli, 2002). A hipoplasia de esmalte local ocorrerá quando a disseminação de uma infecção periapical ou um traumatismo em dente decíduo perturbarem a atividade formadora dos ameloblastos (Toledo, 1996), as causas locais e diretas determinam lesões de distribuição assimétrica, limitadas a dentes isolados e são definidas como hipoplasia de esmalte local (Waes e Stöckli, 2002). Amelogênese imperfeita constitui um grupo de defeitos hereditários do esmalte, não havendo associação com quaisquer outros defeitos generalizados. É uma alteração exclusivamente ectodérmica, pois os componentes mesodérmicos do dente se encontram basicamente normais (Shafer et al., 1987; Pinkham et al., 1996; Corrêa, 1998; Williams e Becker, 2000; Pithan et al., 2002). Afeta ambas as dentaduras e apresenta inúmeras variações clínicas, porém todos os dentes se apresentam mal formados e manchados, podendo afetar severamente a estrutura dentária (McDonald, 1977; Bouvier et al., 1996; Waes e Stöckli, 2002). Segundo Bouvier et al. (1996) a incidência da amelogênese imperfeita é de 1 pessoa para 14000 . Para Williams e Becker (2000), de 1 pessoa para 15000. A hipoplasia hereditária (amelogênese imperfeita) é transmitida como um traço autossômico dominante, um traço dominante ligado ao sexo ou um traço recessivo ligado ao sexo (McDonald, 1977; Williams e Becker, 2000). A oclusão e dimensão vertical são rapidamente afetadas pelo desgaste dos dentes, resultando na ausência de contatos proximais (a estrutura dentária não suporta forças mastigatórias), o que os torna extremamente sensíveis ao contato e estímulos térmicos. Pode ocorrer presença de mordida aberta anterior. Pacientes portadores de distúrbios hereditários são predisponentes a problemas gengivais, devido à aderência e retenção de placa bacteriana, com conseqüente formação de cálculo dental. As coroas dentais têm coloração alterada, variando desde amarelo ao castanho-escuro (dependendo do tipo de manifestação de amelogênese imperfeita ocorrida). Tudo isso, pode acarretar aos pacientes de amelogênese imperfeita, graves problemas psicosociais (Shafer et al., 1987; Bouvier et al., 1996; Jorge et al., 1999; Williams e Becker , 2000; Pithan et al., 2002; Waes e Stöckli, 2002).

Existe concordância entre os autores revisados na literatura, em relação às etiologias e formas de ocorrência de hipoplasia de esmalte sistêmica: hipoplasia devido a deficiências nutricionais, deficiências de Vitamina A, C, D, deficiência de cálcio (hipocalcemia), fósforo e algumas doenças que interferem no metabolismo de cálcio (hipotireoidismo, hipoparatireoidismo e diabete materna não controlada) (Mc Donald, 1977; Shafer et al., 1987; Needleman et al., 1992; Pinkham et al., 1996; Gerlach et al., 2000; Waes e Stöckli, 2002); hipoplasias ocasionadas por efeito da radiação X, (Mc Donald, 1977; Pinkham et al., 1996; Waes e Stöckli, 2002); hipoplasias devido a fluoretos (fluorose dental), ocorre principalmente através da água de abastecimento (Gerlach et al, 2000), que contenha mais de uma parte por milhão (ppm) de flúor, podendo ocasionar um quadro clínico de “esmalte manchado" (McDonald, 1977), em níveis de 0,9 até 1,0 ppm, o fluoreto na água provoca uma pigmentação leve, resultando no "esmalte mosqueado" (Shafer et al., 1987). Os casos mais graves estão associados com o aumento do nível de consumo de flúor (McDonald, 1977; Shafer et al., 1987; Needleman et al., 1992; Pinkham et al., 1996) ou por meio de outras fontes de ingestão de flúor, como em crianças que engolem parte do creme dental, durante a formação do esmalte (Gerlach et al., 2000); hipoplasias ocasionadas ao nascimento: parto prematuro, baixo peso ao nascimento e hipoplasias devido a traumatismos por ocasião do nascimento (Shafer et al., 1987; Needleman et al., 1992; Pinkham et al., 1996; Gerlach et al., 2000); hipoplasias de esmalte devido à sífilis congênita, geralmente envolve os incisivos permanentes supe- 
riores e inferiores e os primeiros molares (Shafer et al., 1987; Pinkham et al., 1996); hipoplasias devido a doenças exantematosas, incluindo: febre exantematosa, (Shafer et al., 1987; Needleman et al., 1992; Carvalho et al. ,2000), sarampo, varicela, escarlatina, rubéola, hipoxia cerebral e desnutrição, (Shafer et al., 1987; Needleman et al., 1992; Gerlach et al., 2000). Entretanto, qualquer doença sistêmica séria pode ser capaz de produzir hipoplasia de esmalte, já que os ameloblastos constituem um dos grupos de células mais sensíveis do corpo, no que diz respeito à função metabólica (Shafer et al., 1987; Seow, 1991; Needleman et al., 1992; Toledo, 1996; Gerlach et al., 2000; Valente e Modesto, 2001); hipolasia devido a fatores idiopáticos (onde a hipoplasia de esmalte é de origem desconhecida), geralmente acomete os primeiros molares permanentes e ocorre em cerca de $7 \%$ das crianças. A intensidade varia desde pequenas manchas no esmalte até graves hipoplasias (Shafer et al., 1987; Waes e Stöckli, 2002); hipoplasias devido à ingestão de medicamentos, como o uso indevido de tetraciclina (Needleman et al., 1992; Corrêa, 1998; Gerlach et al., 2000; Carvalho et al., 2000), ingestão de talidomida e antiinflamatório não esteróides (derivados do ácido pirazolônico) que têm o poder de atravessar a barreira placentária e interferir na formação dos dentes decíduos e permanentes, ocasionando má formação do esmalte dental (Needleman et al., 1992; Gerlach et al., 2000; Carvalho et al., 2000); hipoplasias relacionadas com traumatismos cerebrais e defeitos neurológicos (McDonald, 1977; Needleman et al., 1992; Pinkham et al., 1996). Existem distúrbios relacionados com a ocorrência de hipoplasia de esmalte sistêmica, porém pouco citados na literatura: distúrbios respiratórios, crianças com asma, doença hemolítica do recém-nascido, asfixia neonatal, hipoplasias em forma de canaleta e ocorrência de hipoplasia de esmalte sistêmica relacionada às várias manifestações e tipos de síndromes (Seow, 1991; Needleman et al., 1992; Pinkham et al., 1996; Gerlach et al., 2000; Waes e Stöckli, 2002). Muitos fatores sistêmicos estão associados à ocorrência de hipoplasia de esmalte, portanto, é necessário que o cirurgião-dentista através de um cuidadoso exame clínico chegue ao diagnóstico correto, podendo contribuir através de seus conhecimentos odontológicos para saúde global do paciente (Gerlach et al., 2000).

Geralmente os defeitos locais na estrutura do esmalte dental são decorrentes de trauma ou infecção local (McDonald, 1977; Shafer et al., 1987; Toledo, 1996; Waes e Stöckli, 2002; Hernandes et al., 2003). Para McDonald (1977) Turner foi o primeiro a descrever a hipoplasia do tipo localizada. Portanto hoje hipoplasia local é conhecida como "hipoplasia de Turner” (McDonald, 1977; Shafer et al., 1987; Toledo, 1996; Waes e Stöckli, 2002). Outra forma de manifestação da hipoplasia de esmalte local é através da ocorrência de traumatismo dentário. O traumatismo sobre um dente decíduo pode ocorrer devido à intrusão do dente com alteração do broto do permanente. (McDonald, 1977; Shafer et al., 1987; 1996; Toledo, 1996; Gerlach et al., 2000; Alexandre et al., 2000; Waes e Stöckli, 2002; Hernandes et al., 2003). A pigmentação do dente pode variar conforme o dano ocasionado ao sucessor permanente, desde uma mancha amarelada ou acastanhada do esmalte (Shafer et al., 1987). Para (Alexandre et al., 2000; Gerlach et al., 2000; Hernandes et al., 2003), a luxação intrusiva é o tipo de traumatismo dentário que mais acarreta aparecimento de hipoplasia de esmalte local, sendo as crianças menores mais sujeitas a traumas dentários e a região da maxila mais atingida. Alexandre et al. (2000) relatam que as luxações são responsáveis por 60 a 73\% dos casos de traumatismos dentários. A freqüência com que o desenvolvimento normal do dente permanente é afetado após a intrusão dos dentes decíduos pode chegar a $50 \%$ e geralmente o incisivo central superior é o dente mais envolvido. Hernandes et al. (2003), concluem que aproximadamente $30 \%$ das crianças de 10 a 72 meses já sofreram algum tipo de trauma nos dentes decíduos. É muito importante saber quando, onde e como aconteceu o traumatismo dentário, para que se possa estabelecer um diagnóstico preciso durante o atendimento emergencial, para posterior planejamento definitivo (Alexandre et al., 2000; Hernandes et al., 2003).

Na subdivisão de amelogênese imperfeita, ocorrem variações quanto à sua manifestação, 
alteração e estágios de desenvolvimento do esmalte dental: amelogênese imperfeita hipoplásica, há formação deficiente da matriz orgânica, resultando em formação de esmalte insuficiente. Os dentes aparecem pequenos, com pontos de contato abertos, esmalte muito fino ou inexistente (ocasionando aumento de sensibilidade), presença de placa dental e ocorrência de mordida aberta anterior. Geralmente a condição é herdada predominantemente como característica autossômica dominante, acarretando manifestações clínicas na coroa dental, tais como: forma crateriforme, forma áspera, forma lisa e a maioria das manifestações de formas locais. Amelogênese imperfeita tipo hipomineralizada, onde há mineralização deficiente de matriz orgânica formada. Quantitativamente o esmalte é normal, mas qualitativamente a matriz é pobremente mineralizada. $\mathrm{O}$ esmalte se apresenta mole, frágil, opaco e com coloração variável, podendo atingir toda sua espessura, devido à formação deficiente de cristalitos. Nas regiões incisais é facilmente fraturado expondo a dentina, que produz aparência sem estética. Amelogênese imperfeita tipo hipomaturada, a espessura do esmalte é normal, porém apresenta baixo valor de radiodensidade e conteúdo mineral, ocorrendo presença de superfície porosa que conseqüentemente se torna pigmentada (Shafer et al., 1987; Pinkham et al., 1996; Waes e Stöckli, 2002).

Nos dentes decíduos geralmente são fatores ambientais que alteram o esmalte durante o período de formação do dente, e suas manifestações clínicas são mais suaves, pois o período de formação e a espessura do esmalte dos dentes decíduos são menores (Seow, 1991). Já Corrêa (1998) diz que a hipoplasia de esmalte em dentes decíduos por meio de fatores sistêmicos e locais é rara. Gerlach et al. (2000) descrevem que uma das formas de acometer a dentadura decídua é durante a entubação endotraqueal, que pode resultar em trauma do osso em desenvolvimento.

Em relação à cárie dental associada à ocorrência de hipoplasias de esmalte sistêmica, McDonald (1977) relatou que existem poucas evidências para afirmar que dentes hipoplasiados são mais suscetíveis à cárie que os dentes normais. Para Shafer et al.(1987), as duas não estão relacionadas. Porém, lesões de cárie podem se desenvolver em defeitos de esmalte e ter uma evolução mais rápida (McDonald, 1977; Shafer et al., 1987).

Os métodos de tratamento empregados para reabilitação de hipoplasia de esmalte sistêmica dependem da extensão do processo carioso associado a hipoplasia de esmalte. Pequenas lesões de cárie e áreas pré-cariosas podem ser restauradas com materiais resinosos, lembrando que a restauração é sempre restrita a área envolvida. Em caso de dentes decíduos e permanentes que apresentam amplas áreas de esmalte defeituoso e dentina exposta, logo que irrompam podem se apresentar sensíveis, nessa época restaurações satisfatórias são praticamente impossíveis, então pode ser realizada a aplicação tópica de fluoreto estanoso a oito por cento quantas vezes for necessário para ocorrer à redução da sensibilidade dos dentes afetados (McDonald, 1977; Coutinho e Portella, 1995). Franco et al. (2001), citaram o uso de diversas técnicas, propostas para resolver casos de manchamento dentário, tais como: clareamento dental, microabrasão, restaurações diretas e indiretas em resina composta e porcelana. Entretanto, técnicas menos invasivas podem ser selecionadas quando o dente não estiver excessivamente danificado, pois em casos de manchamento severo ou perda de estrutura dentária, procedimentos restauradores estão indicados.

È de grande importância o pronto-atendimento, tratamento precoce, e acompanhamento do paciente após ocorrer qualquer tipo de trauma ou infecção localizada, a fim de evitar ou minimizar alterações, ou possíveis seqüelas no dente permanente (Alexandre et al., 2000; Hernandes et al., 2003). Marangoni e Carvalho (1992), avaliaram formas de restabelecer a estética em dentes anteriores acometidos por hipoplasia de esmalte localizada, as soluções encontradas foram: uso de coroas totais em metalocerâmica, facetas estéticas em porcelana e restaurações estéticas com o uso de resina composta. Para McDonald (1977); Williams e Becker (2000), em pacientes portadores de amelogênese imperfeita, é necessário que se realize um plano de tratamento meticuloso, por meio de diagnóstico preciso e detalhado (o que dependerá da severidade e necessidade de melhorar a estética), evitando ou diminuindo as seqüelas decorrentes do distúrbio. Segundo Jorge et al. (1999) em pacientes 
que apresentam amelogênese imperfeita, devido a sua origem genética, não há como realizar tratamento preventivo. Portanto, em portadores deste distúrbio hereditário, o tratamento é voltado somente para aspecto estético. Waes e Stöckli (2002) citaram que o tratamento destes pacientes deve ser iniciado com instituição de programa de prevenção. Bouvier et al. (1996) relatam que deve-se iniciar, com tratamento emergencial temporário dos dentes decíduos ou permanentes (tratamento breve), para posterior realização da etapa transitória, em que serão realizadas restaurações provisórias, com o objetivo de criar condições propícias para procedimentos preventivos, e assegurar desenvolvimento da dentição sem distúrbios. Esta etapa ocorre após erupção de todos os dentes permanentes (exceto terceiros molares) e somente será realizada se o paciente aceitar e/ou permitir ter vida normal até que um tratamento definitivo, permanente e mais complexo seja planejado e executado. A grande vantagem desta fase é restabelecer a estética funcional. O tratamento definitivo da amelogênese imperfeita deve ser realizado após restabelecimento de oclusão, dimensão vertical, higiene bucal, função, completa erupção dentária, término do crescimento e preparo do paciente para receber execução de tal procedimento, tendo como objetivo ser duradouro e ter elevado grau estético e funcional (Bouvier et al., 1996; Williams e Becker, 2000; Waes e Stöckli, 2002). Geralmente os pacientes que apresentam amelogênese imperfeita são candidatos a terapêutica reabilitadora por coroas totais, devido ao aspecto estético estar seriamente afetado e ao desgaste excessivo dos dentes (muitas vezes até o nível gengival) (Williams e Becker, 2000; Pithan et al., 2002). Os tratamentos executados em pacientes que apresentam amelogênese imperfeita, geralmente são complexos e demorados, dependendo da gravidade da alteração (McDonald, 1977; Shafer et al., 1987; Bouvier et al., 1996; Pinkham et al., 1996; Jorge et al., 1999; Williams e Becker, 2000; Pithan et al., 2002; Waes e Stöckli, 2002). Tratamento reabilitador satisfatório é aquele que promove uma completa reconstituição estética e devolve ao paciente a função mastigatória (McDonald, 1977; Coutinho e Portella, 1995).
Entretanto, o objetivo principal do tratamento das hipoplasias de esmalte é restabelecer à plena recuperação anatômica e harmonia entre oclusão, função e estética, devolvendo ao paciente sua autoestima e promovendo benefícios psicológicos e sociais (Alexandre et al., 2000; Pithan et al., 2002; Waes e Stöckli, 2002; Hernandes et al., 2003).

\section{Conclusão}

Uma grande variedade de anomalias dentárias estão associadas a defeitos no desenvolvimento dos dentes, ocasionadas por hereditariedade, fatores locais, sistêmicos ou traumáticos, podendo afetar as dentições decídua e/ou permanente. Mesmo com todos os avanços científicos e tecnológicos na Odontologia, ainda não foi possível evitá-las, entretanto, o tratamento poderá ser efetivo e eficaz, desde que o cirurgião-dentista realize uma anamnese e um diagnóstico diferencial adequados.

Quanto às anomalias de estrutura do esmalte, estas se manifestam como hipoplasias que desencadeiam alterações de cor e defeitos variáveis, dependendo do grau de severidade do distúrbio ocorrido. De acordo com a literatura, não foi comprovada a associação de hipoplasias de esmalte com o desenvolvimento de lesões de cárie, porém em cavidades hipoplásicas com processos cariosos já instalados, a evolução é mais rápida.

No tratamento das anomalias que acometem o esmalte é de fundamental importância restabelecer a harmonia estética, funcional e psicológica dos pacientes portadores destas alterações o mais precocemente possível, associando o conhecimento e habilidade do profissional aos materiais odontológicos de última geração.

\section{REFERÊNCIAS}

1 ALEXANDRE, G. C.; CAMPOS, V.; OLIVEIRA, B. H. Luxação Intrusiva de Dentes Decíduos. São Paulo, mai./jun. 2000. Disponível em: http://www.apcd.org.br/Biblioteca/ Revista/2000maio_jun/219asp. Acesso em: 08 out. 2003. 
BOUVIER, D.; DUPREZ, J. P.; BOIS, D. Rehabilitation of young patients with amelogenesis imperfecta: A report of two cases. Journal of Dentistry for Children, Chicago, v. 63, n. 6, p. 443-447, nov./dec. 1996.

CARVALHO, K.; ZARDINI, F.; SIPOLATTI, K. O cuidado com os dentes começa na barriga da mamãe. Vitória, maio 2002. Disponível em: http://www.escelsanet.com.br/ sitesaude/artigos_cadastrados. Acesso em: 02 out. 2003.

CORRÊA, M. S. N. P. Radiologia em odontologia. In: Odontopediatria - Na Primeira Infância. São Paulo: Santos, 1998. cap. XVIII, p. 209-219.

COUTINHO, T. C. L.; PORTELLA, W. Hipoplasia de Esmalte: Tratamento com Facetas Estéticas e Coroas de Aço. Rev. RGO, Porto Alegre, v.43, n.2, p.89-92, mar./abr. 1995.

ELZAY, R. P.; CHAMBERLAIN, D. H. Differential diagnoses of enlarged dental pulps chambers: a case report of amelogenesis imperfecta with taurodontismo. Journal of Dentistry for Children, Chicago, v. 53, n. 5, p. 388-390, sept./oct. 1986.

FRANCO, E. B.; ALMEIDA, J. C. F.; GARCIA, F. C. P. Recuperação estética do sorriso através de colagem autógena de fragmento dentário e restauração com resina composta: caso clínico. Rev. JBC J. Bras. Clín. Estét. Odontol., Bauru, v.5, n.26, p.104-110, mar./abr. 2001.

GERLACH, R. F.; SOUSA, M. da L. R. de; CURY, J.A. Esmalte Dental com Defeitos: de marcador biológico a implicações clínicas. Rev. Odonto Ciência, Porto Alegre, v.15, n.31, p.87-102.

HERNANDES, M. C. C. O.; GOULART, M. M.; PALECKIS, L. G. P. Trauma em Dentição Decídua e suas Conseqüências na Dentição Permanente: Relato de um caso clínico. São Paulo, jun. 2003. Disponível em: http:// www.apcd.com.br/ rev-art. Acesso em 02 out. 2003.

JORGE, M. A.; ROSLINDO, E. B.; RAMALHO, L. T. de O.; UTRILLA, L. S.; IOST, H. I. Amelogênese Imperfeita ligada - X. Rev. RGO, Porto Alegre, v.47, n.2, p.89-90, abr./ mai./jun. 1999.

MARANGONI, M. H.; CARVALHO, R. M. Dentística Cosmética: em hipoplasia de esmalte. Rev. RGO, Porto Alegre, v.40, n.5, p.344-345, set./out. 1992.
MCDONALD, R. E. Alterações no Desenvolvimento dos Dentes e Maxilares. In: Odontopediatria. 2. ed. Rio de Janeiro: Guanabara Koogan, 1977. cap.4, p.40-63.

NEEDLEMAN, H. L.; ALLRED, E.; BELLINGER, D.; LEVITON, A.; RABINOWITZ, M.; IVERSON, K. Antecedents and correlates of hypoplastic enamel defects of primary incisors. Pediatric Dentistry, v.14, n.3, p.158-166, may/jun. 1992.

OLIVEIRA, A. F. B.; ROSEnBLATT, A. Defeitos do Esmalte: o que o odontopediatra precisa saber. Rev. ABO Nac., São Paulo, v.10, n.5, p.274-277, out./nov. 2002

PINKHAM, J. R.; CASAMASSIMO, P. S.; FIELDS; MCTIGUE; NOVAK. Anomalias de Desenvolvimento da Dentição. In: Odontopediatria da Infância à Adolescência. 2. ed. São Paulo: Artes Médicas, 1996. cap.4, p.63-76.

PITHAN, J. C. de A.; MALMANN, A.; PITAN, S. A.; COSTA, C. C. Amelogênese Imperfeita: revisão de literatura e relato de caso clínico. Rev. ABO Nac., São Paulo, v.10, n.2, p.88-92, abr./mai. 2002.

SEOW, W. K. Enamel hypoplasia in the primary dentition: a review. ASDC J. Dent. Child., Chicago, v.58, n.6, p.441452, nov./dec. 1991.

SHAFER, W. G.; HINE, M. K.; LEVY, B. M. Distúrbios do Desenvolvimento das Estruturas Bucais e Parabucais. In: Tratado de Patologia Bucal. 4. ed. Rio de Janeiro: Guanabara Koogan, 1987. cap.1, p.02-79.

TOLEDO, O. A. Crescimento e Desenvolvimento Noções de Interesse Odontopediátrico. In: Odontopediatria: fundamentos para a prática clínica. 2. ed. São Paulo: Premier, 1996. cap.1, p.17-40.

VALENTE, A. G. L. R.; MODESTO, A. Seqüelas Odontológicas de Problemas Sistêmicos. Rev. JBP, Curitiba, v.4, n.17, p.58-61, jan./feb. 2001.

WAES, H. J. M.; STÖCKLI, P. W. Odontopediatria. Porto Alegre: Artmed, 2002. p.385.

WILLIAMS, W. P.; BECKER, L. H. Amelogenesis imperfecta: Functional and esthetic restoration of a severely compromised dentition. Quintessence International, Chicago, v.31, n. 6, p. 397-403. jun.2000. 